LBNL-62459

\title{
The Liquefaction of Hydrogen and Helium Using Small Coolers
}

\author{
Michael A. Green \\ Lawrence Berkeley National Laboratory \\ Berkeley CA 94720, USA
}

12 February 2007*

\begin{abstract}
This report discusses the history of the liquefaction of hydrogen and helium using small coolers. This history dates form the 1960's when two stage GM coolers capable of reaching $7 \mathrm{~K}$ were used to liquefy helium and hydrogen by suing an added compressor and $\mathrm{J}-\mathrm{T}$ circuit. Liquefaction using the added circuit failed to become mainstream because the J-T valve and heat exchanger clogged because of impurities in the gas being liquefied. Liquefaction using a GM cooler without an added J-T circuit proved to be difficult because the first stage was not used to pre-cool the gas coming to the second stage of the cooler. Once the gas being liquefied was pre-cooled using the cooler first stage, improvements in the liquefaction rates were noted. The advent of low temperature pulse tube cooler (down to $2.5 \mathrm{~K}$ ) permitted one to achieve dramatic improvement is the liquefactions rates for helium. Similar but less dramatic improvements are expected for hydrogen as well. Using the PT-415 cooler, one can expect liquefaction rates of 15 to 20 liters per day for helium or hydrogen provided the heat leak into the cooler and the storage vessel is low. A hydrogen liquefier for MICE is presented at the end of this report.
\end{abstract}

\section{TABLE OF CONTENTS}

Abstract

Page

Introduction

1.

What is difficult about liquefying Gasses using a Small Cooler?

2 .

Liquefaction using a cooler with a Separate a J-T circuit on a GM Cooler

3.

Liquefaction of Why Liquefaction of Hydrogen of Helium is better using a

Pulse Tube cooler Alone helium using a GM Cooler Alone

4.

5.

Why Liquefaction of Helium and Hydrogen may be Better using a

Pulse Tube cooler Alone?

The Liquefaction of Hydrogen Gas into the MICE Absorber

Using a Cryomech PT-415 Cooler

12.

The Proposed LBNL PT-415 Cooler Experiment 15

Some Concluding Comments

17.

Acknowledgements

18.

References

18.

* Last revision 12 February 2007 


\section{Introduction}

The liquid absorbers for MICE are designed to be filled with liquid hydrogen at about $21 \mathrm{~K}$ using a $4 \mathrm{~K}$ cooler [1]. Once the absorber is filled, it may operate over a temperature range from about $16 \mathrm{~K}$ to $21 \mathrm{~K}$. If the heat leak is low enough, it is hoped that the MICE liquid absorbers can be filled with liquid helium as well. The liquid absorber has particular safety issues when it is filled with liquid hydrogen. The safety issues for the MICE liquid absorber are different if the absorbers are filled with liquid helium instead of liquid hydrogen. The RAL safety committee has chosen to put similar safety constraints on the filling of the liquid absorbers with liquid helium as with liquid hydrogen. A close analysis of the issue of filling absorbers with liquid helium will clearly show that the RAL safety committee analysis (or the interpretation of the safety committees findings) is in error. The RAL safety committee does not allow the absorber to be filled with liquid hydrogen from a dewar. Apparently there is a prohibition from filling the liquid absorber with liquid helium from a dewar as well, despite the fact that helium is transferred from one dewar to another everyday without safety committees being upset about it.

Small two stage GM coolers have been used to liquefy both helium and hydrogen since the 1960's [2]. Early two-stage coolers (before about 1995) had a low-end temperature of about 7 to $8 \mathrm{~K}$. In order to liquefy helium into a cryostat a separate J-T valve and J-T heat exchanger had to be used. It wasn't until about 1996, when a new class of regenerator materials were developed did two stage coolers reach temperatures below $4 \mathrm{~K}$. The first of these new coolers that became available were GM coolers. Within a few years similar performance was being achieved using two-stage pulse tube coolers. A number attempts at using two-stage GM and pulse tube coolers, without an added J-T circuit and heat exchanger, to liquefy helium have been tried some success. Pulse tube coolers are well suited for helium and hydrogen liquefaction because the pulse tube and regenerator tubes on both stages can be involved in pre-cooling the gas being liquefied. Such notions have been met with skepticism despite the fact this has been demonstrated on a number of successful systems. The skepticism is driven by the fact that similar improvement in liquefaction performance has not been seen when GM coolers have been used to liquefy hydrogen or helium.

The critical factors that govern the liquefaction of hydrogen or helium is the sensible heat that needed to be removed using the upper-stage of the cooler compared to the heat of vaporization that must be removed by the second-stage of the cooler. The problems associated with coolers use J-T circuits and J-T heat exchangers to liquefy gasses are shown. The critical steps needed to liquefy hydrogen or helium using a $4 \mathrm{~K} \mathrm{GM}$ cooler are shown. The theoretical performance of a GM cooler liquefier is presented and compared with the KEK absorber cooling experiment [3].

The development of helium liquefaction using a pulse tube cooler is presented. This report will demonstrate that the pulse tubes and regeneration tubes between the $300 \mathrm{~K}$ top plate and the pulse tube cooler first stage and between the cooler first stage and the second stage will significantly improve the pre-cooling of the gas being liquefied on a condenser mounted on the second stage. Cryomech has demonstrated this on their helium liquefiers that are currently being marketed.

The conceptual design of a MICE absorber liquefier using the Cryomech PT-415 cooler is shown in this report. Cryomech could build this liquefier for MICE, if the management of the MICE AFC module decides that this is the correct direction to go. 


\section{What is difficult about liquefying Gasses using a Small Cooler?}

The upper limit for liquefaction possible using a cooler is governed by the available refrigeration on the second stage cold head and the heat of vaporization $h_{f g}$ of the fluid being liquefied [4]. For example, the maximum available refrigeration at $4.2 \mathrm{~K}$ for helium on a PT- 415 cooler is $1.5 \mathrm{~W}$. The $h_{f g}$ for helium at $4.2 \mathrm{~K}$ is $20.7 \mathrm{~J} \mathrm{~g}^{-1}$. This means that the maximum amount of helium that can be liquefied is about $0.075 \mathrm{~g} \mathrm{~s}^{-1}$ (about 2.2 liters per her hour) For example, the maximum available refrigeration at $20.3 \mathrm{~K}$ for any cooler is $\sim 20 \mathrm{~W}$. The $h_{f g}$ for hydrogen is about $445 \mathrm{~J} \mathrm{~g}^{-1}$. This means that the maximum amount of hydrogen that can be liquefied is about $0.045 \mathrm{~g} \mathrm{~s}^{-1}$ (about 2.3 liters per hour) with perfect gas pre-cooling and zero heat leak. The best-case liquefaction refrigeration coefficient is the heat of vaporization, with perfect gas pre-cooling and zero heat flow into the cryostat. Since the gas pre-cooling going into the second stage is imperfect and the heat leak into the liquid cryostat is not zero, the actual liquefaction using any cooler will be much lower than the values given earlier in this paragraph.

The sensible change of enthalpy between the boiling temperature $T_{B}$ and $300 \mathrm{~K}$ is given by the following expression.

$$
\Delta H_{\text {sen }}=\int_{T_{B}}^{300 K} C_{p}(T) d T
$$

where $C_{p}$ is the specific heat at constant pressure per unit mass $\left(\mathrm{J} \mathrm{g}^{-1} \mathrm{~K}^{-1}\right)$; and $\mathrm{T}$ is temperature $(\mathrm{K})$.

For helium, the value of $\mathrm{C}_{\mathrm{p}}$ is essentially constant at $5.2 \mathrm{~J} \mathrm{~g}^{-1} \mathrm{~K}^{-1}$ from $5 \mathrm{~K}$ to $300 \mathrm{~K}$ at a pressure of 1 bar. Thus the total sensible enthalpy between $4.2 \mathrm{~K}$ and $300 \mathrm{~K}$ is about $1540 \mathrm{~J} \mathrm{~g}^{-1}$. For hydrogen the value of $\mathrm{C}_{\mathrm{p}}$ varies from about $9 \mathrm{~J} \mathrm{~g}^{-1} \mathrm{~K}^{-1}$ to $14.2 \mathrm{~J} \mathrm{~g}^{-1} \mathrm{~K}^{-1}$. The total sensible enthalpy from $20.3 \mathrm{~K}$ to $300 \mathrm{~K}$ is about $4000 \mathrm{~J} \mathrm{~g}^{-1}$. For helium the sensible heat is about 75 times the latent heat. For hydrogen, the sensible heat is about 9 times the latent heat. The numbers of hydrogen are more approximate because there is the ortho to para transition heat. The ortho to para transition energy for a gram of normal hydrogen at $20 \mathrm{~K}$ (about 75 percent ortho hydrogen) is about $300 \mathrm{~J} \mathrm{~g}^{-1}$. In general the transition time for hydrogen from the ortho state to the para state takes days. Liquid hydrogen that has been sitting around for ten days or so is essentially all para hydrogen.

In order to liquefy $0.076 \mathrm{~g} \mathrm{~s}^{-1}$ of helium, one must remove $117 \mathrm{~W}$ of sensible heat from the gas that is condensed on the second-stage of the cooler. This is unlikely to occur even under the best of circumstances for most coolers. Liquid nitrogen pre-cooling combined with proper heat exchangers might permit a $1.5 \mathrm{~W}$ cooler to liquefy close to $0.07 \mathrm{~g} \mathrm{~s}^{-1}$ of helium. The problem is reducing the heat leak into that cryostat.

In order to liquefy $0.045 \mathrm{~g} \mathrm{~s}^{-1}$ of hydrogen, one must remove $180 \mathrm{~W}$ of sensible heat from the gas that is condensed on the second-stage of the cooler. This is unlikely to occur even under the best of circumstances. Liquid nitrogen pre-cooling might permit the cooler (under the best of circumstances) to liquefy $0.04 \mathrm{~g} \mathrm{~s}^{-1}$ of hydrogen using a $20 \mathrm{~W}$ (at $20.3 \mathrm{~K}$ ) cooler. Again an important problem in the process is getting the heat leak into the cryostat down to as low a value as possible.

The keys of liquefying either hydrogen or helium using a cooler are; 1) minimizing the heat leak into the region where the liquefaction occurs and 2) maximizing the efficiency of heat transfer in the upper stages of the cooler and between stages of the cooler. Nitrogen pre-cooling can also be a factor. 


\section{Liquefaction using a cooler with a Separate a J-T circuit on a GM Cooler}

The first single stage GM coolers could only go down to about 50 or $60 \mathrm{~K}$. The first two stage coolers came out in the mid 1960's. These machines could reach 10 to $15 \mathrm{~K}$ at first. Later the minimum temperature dropped to the 7 or $8 \mathrm{~K}$ range, when a lead shot regenerator was used. Since the second stage temperature was less than the J-T inversion temperature for helium, it was felt that by using a separate J-T circuit one should be able to liquefy helium [5]. Figure 1 shows a two-stage GM cooler with lead shot regenerators with a separate $\mathrm{J}-\mathrm{T}$ circuit used to liquefy helium.

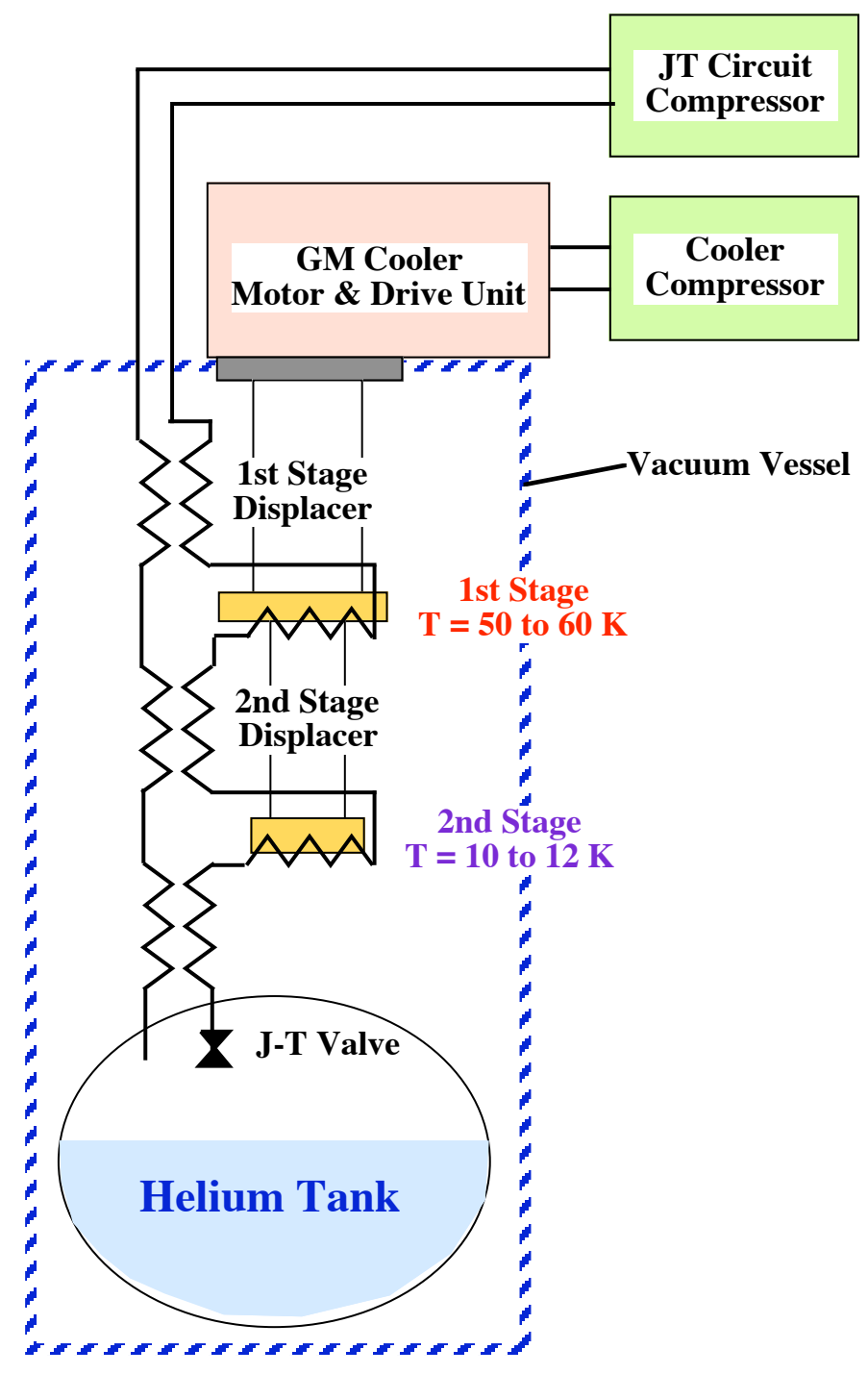

Figure 1. A Conventional GM Cooler with an Added J-T Circuit for Liquefying Helium

The machine shown in Figure 1 was the way coolers were used to provide helium refrigeration at $4.2 \mathrm{~K}$ before about 1997, when the first GM cooler with rare-earth regenerators came out. A number of companies manufactured GM coolers with the option of adding a separate J-T circuit. These coolers were made by companies such a CTi, APD and Daicon. With the exception of CTi, which no longer makes coolers with $\mathrm{J}-\mathrm{T}$ circuits, these companies have been purchased by Sumitomo in Japan. 
The cooler arrangement shown in Figure 1 can produce refrigeration at $4.5 \mathrm{~K}$ in the 1.5 to $2.0 \mathrm{~W}$ range. More modern versions of these machines can produce up to $7 \mathrm{~W}$ of cooling below $5 \mathrm{~K}$. The real problem with any of the separate J-T circuit machine was reliability. Not only does one have the maintenance interval associated with GM machines and their compressors, but one also has the reliability problems associated with the extra compressor and the problem of clogging a J-T valve with impurities in the gas.

As liquefiers, the separate J-T circuit machines were less than satisfactory. The cooling available at the first stage was often a poor match for the cooling needed for precooling gas to be liquefied. The gas liquefied does not return up the J-T heat exchanger. In a conventional Claude cycle machine one balances the flow in the heat exchangers during liquefaction by running more gas through the expansion engines. This option is not available on a cooler, which is set up to maximize refrigeration at the low temperature end. A typical large Claude cycle machine will have a refrigeration to liquefaction ratio for helium of 75 to $130 \mathrm{~J} \mathrm{~g}^{-1}$ (W of refrigeration divided by $\mathrm{g} \mathrm{s}^{-1}$ of liquefaction). When a GM machine with an additional $\mathrm{J}-\mathrm{T}$ circuit is used as a helium liquefier, the refrigeration to liquefaction ratio was always much higher (sometimes as high as $350 \mathrm{~J} \mathrm{~g}^{-1}$ ). Thus it was always difficult to cool a superconducting magnet with conventional gas cooled leads using a cooler with a J-T circuit. The helium flow up conventional gas cooled leads is always liquefaction. Magnets with retractable leads could be kept cold using a GM cooler with an added J-T circuit, but reliability was always an issue. HTS leads (only available since the early 1990's) made things better, but cooler reliability was still an issue until the first 4 K GM coolers became available in the mid 1990's.

\section{Liquefaction of hydrogen or helium using a GM Cooler Alone}

The advent of two-stage coolers (both GM and pulse tube) with the new class of rare-earth regenerators changed the cooler business and the business of cooling things with coolers. The first GM coolers with the new rare-earth regenerators came into being about 1996 [6]. The new regenerator permitted the second-stage temperature to be dropped from about $7 \mathrm{~K}$ to about $2.5 \mathrm{~K}$. The limiting factors with the new regenerator materials is not the specific heat of the regenerator, but the specific heat of the helium, which is the working fluid for the cooler. The lower limit for the second-stage temperature is dictated by the specific heat of the helium being cooled in the cooler. The helium 4 isotope goes through a lambda transition (with very high helium specific heats) at $2.17 \mathrm{~K}$. Helium 3 does not undergo a lambda transition at any temperature. As a result, coolers that have the helium 3 isotope as a working fluid can go down to temperatures as low as $1.4 \mathrm{~K}$ at zero heat leak into the cooler second-stage cold head.

Hydrogen liquefaction did not require the advent of the new regenerator material. One could achieve about $20 \mathrm{~W}$ of cooling on the second stage of a cooler using the old regenerator. The key to liquefying helium with the new coolers and hydrogen using coolers has always been the ability to pre-cool the gas using the upper stages of the cooler before trying to liquefy the gas using the second stage cold head of the cooler. With the rare-earth regenerator material, if became possible to use direct condensation on the cooler second stage in order to get liquid helium or hydrogen into a cryostat. In general, any type of cooler with an efficient second-stage condenser can be used for recondensation of helium or hydrogen. However, this re-condensation is not liquefaction in the traditional sense, where a device is filled with liquid from a $300 \mathrm{~K}$ gas source. 
Early experiments on GM coolers with the rare-earth regenerator as liquefiers were not very successful. The key to liquefying hydrogen or helium is pre-cooling before it enters the condenser region of the cooling loop. Figure 2 shows a diagram for liquefying liquid helium (or liquid hydrogen) using a modern GM cooler where a J-T circuit is not needed to achieve temperatures below $5 \mathrm{~K}$. Having the helium or hydrogen condenser as part of a thermal siphon loop is key to achieving good liquefaction and a reduction of the $\Delta \mathrm{T}$ between the cooler second-stage cold head and the load being cooled or cooled down using the cooler.

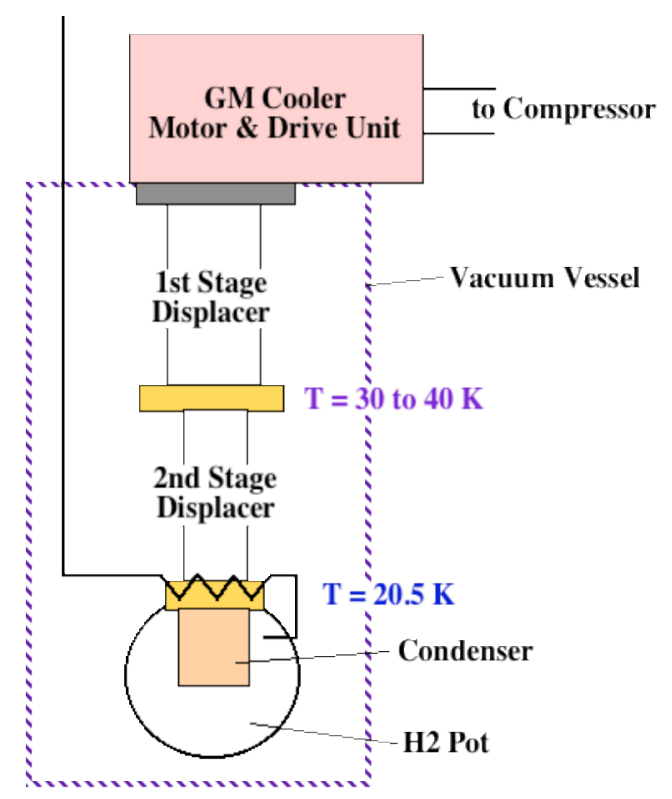

a) LH2 Liquefier without Ist Stage Heat Exchanger

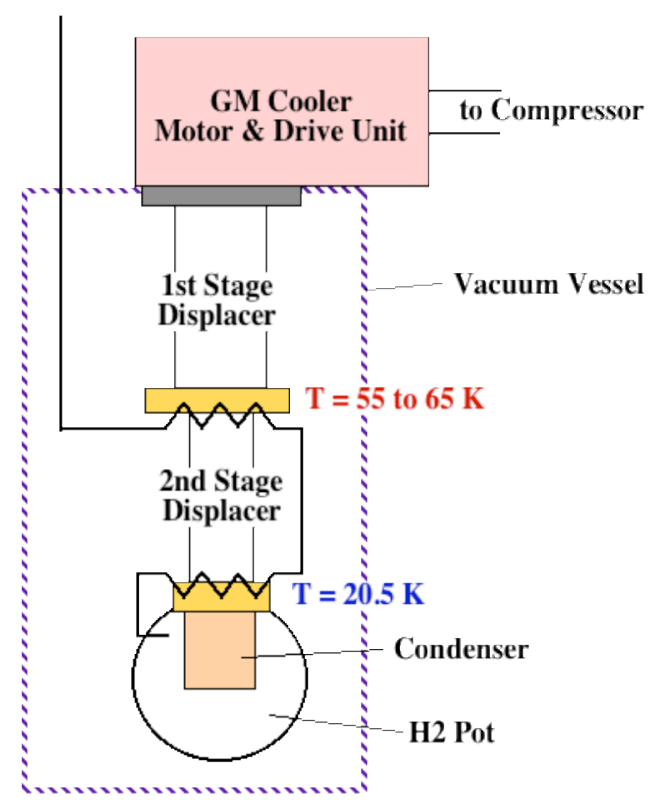

b) LH2 Liquefier with 1st Stage Heat Exchanger

Figure 2. A Liquefaction Schematic for Using Modern GM Coolers for Liquefaction $\mathrm{LH}_{2}$ or LHe.

The left hand part of Figure 2 shows all of the pre-cooling heat exchange on the second stage of the GM cooler. If the heat exchanger were perfectly efficient, the liquefaction of helium would be about $0.001 \mathrm{~g} \mathrm{~s}^{-1}$ for a cooler that develops about $1.5 \mathrm{~W}$ (at $4.2 \mathrm{~K}$ ) on the second-stage cold head. If liquid nitrogen is used to pre-cool the helium, the liquefaction will go up to $0.004 \mathrm{~g} \mathrm{~s}^{-1}$ The addition of an efficient heat exchanger on the cooler first-stage (see the right hand part of Figure 2) will improve the liquefaction of helium to something that is about $0.008 \mathrm{~g} \mathrm{~s}^{-1}$. Pre-cooling the helium entering the liquefier with liquid nitrogen will improve the liquefaction to something that approaches $0.015 \mathrm{~g} \mathrm{~s}^{-1}$. Using the heat exchanger on the first-stage alone means that the refrigeration to liquefaction coefficient will be $\sim 200 \mathrm{~J} \mathrm{~g}^{-1}$.

For hydrogen liquefaction things are somewhat better. If all of the pre-cooling heat exchange is on the second stage, the maximum liquefaction rate will be about $0.005 \mathrm{~g} \mathrm{~s}^{-1}$ for a cooler that produces $20 \mathrm{~W}$ (at $20 \mathrm{~K}$ ). Liquid nitrogen pre-cooling alone improves this to $0.020 \mathrm{~g} \mathrm{~s}^{-1}$. A first stage heat exchanger alone will improve produce a liquefaction of $0.027 \mathrm{~g} \mathrm{~s}^{-1}$. Adding $\mathrm{LN}_{2}$ pre-cooling to a perfectly efficient heat exchanger on the first stage will improve the rate of hydrogen liquefaction to about $0.033 \mathrm{~g} \mathrm{~s}^{-1}$. One can get a refrigeration to liquefaction coefficient approaching $\sim 600 \mathrm{~J} \mathrm{~g}^{-1}$, which is excellent [7]. 
The preceding calculations assume that the heat transfer with in the heat exchanger is very good and that the pinch temperatures are low compared to the absolute temperature of the gas in the heat exchangers. In a practical system the use of liquid nitrogen pre-cooling heat exchanger is unlikely, because of the added expense and complication to the system. The only way that one can substantially improve the efficiency of the system is to have more stages of cooling in the GM cooler and one must have a heat exchanger on each stage of the GM cooler.

In general, GM coolers deliver all of their cooling on the cold head for that stage. There is little cooling that occurs between stages of the GM cooler. The most common 4.2 K coolers that are available are manufactured by Sumitomo Industries. In a GM cooler produced by Sumitomo or other manufacturers, the surface of the stainless steel tube between stages is quite well insulated from the moving pistons and the regenerator material. As a result, little in the way of meaningful cooling can be produced between the cooler stages. This has interesting implications on how the coolers are mounted and whether the cooler works well in a neck filled with helium gas (in the case of a superconducting magnet cooled with a pop in GM cooler).

\section{Why Liquefaction of Helium and Hydrogen may be Better using a Pulse Tube cooler Alone}

Commercial two-stage $4 \mathrm{~K}$ pulse tube coolers came into being in the 1990's. One of the first ones was a $0.25 \mathrm{~W}$ cooler (at $4.2 \mathrm{~K}$ ) produced by Leibolt in Germany. Cryomech in the United States started producing pulse tube coolers in about 2000 [8]. At first these coolers were limited to a maximum cooling power of $0.5 \mathrm{~W}$. Later this cooling power was increased to $0.7 \mathrm{~W}$ and then $1.0 \mathrm{~W}$ at $4.2 \mathrm{~K}$. The first Cryomech $1.5 \mathrm{~W}$ coolers went on the market in late 2005. The pulse tube coolers produced by Cryomech are direct competition for the $0.5 \mathrm{~W}$ to $1.5 \mathrm{~W}$ (at $4.2 \mathrm{~K}$ ) GM coolers produced by Sumitomo. Sumitomo is also producing $4.2 \mathrm{~K}$ pulse tube coolers. At the time this report was written, the peak cooling power for the Sumitomo pulse tube coolers was $\sim 1 \mathrm{~W}$. In reality there are only two companies that are capable of producing commercial coolers that produce up to $1.5 \mathrm{~W}$ at $4.2 \mathrm{~K}$. The field is changing so this assessment may not hold with time.

Pulse tube coolers are not the same animal as GM coolers. Each type of cooler has its own niche in the marketplace. A few examples are as follows: 1) If wants a cooler cold head that will operate at almost any orientation, one must use a GM cooler. Pulse tube coolers must operate with the cold end down and the warm end up. 2) If wants very low vibration in a situation where the cooler can be oriented optimally, one would gravitate toward a pulse tube cooler because the cooler cold head vibrates with two orders of magnitude less than a GM cooler. 3) Pulse tube coolers tolerate magnetic field much better than GM coolers. The cold heads and GM cooler drive units cannot withstand a magnetic field of more than $0.1 \mathrm{~T}$. The only part of a pulse tube cooler that is magnetic field sensitive is the rotary valve drive motor. The pulse tube drive motor is relatively easy to shield to a field of $0.4 \mathrm{~T}$ and the motor can be moved to a location up to 1-meter from the rest of the cold head assembly. 4) The maintenance interval for a pulse tube cooler cold head is in excess 25000 hours (compared to a required maximum interval of 12000 hours for a GM cooler cold head). The only part that may need maintenance in a pulse tube cooler is the rotary valve. With modern pulse tube coolers, it is not clear that the valve needs any maintenance at all. 
The method by which one mounts a pulse tube cooler onto the load being cooled (for example a superconducting magnet) may be very different from the preferred method for mounting a GM cooler onto a load. Some pulse tube coolers, but not all, can be dropped into a helium cryostat through the neck of the cryostat that fits around the cooler. The reason for this is that heat that comes down the neck of the cryostat that the pulse tube cooler is dropped into can be intercepted by natural convection and be deposited onto the pulse tubes and regenerator tubes. This concept will be explained later in this report. If one drops a GM cooler into a helium cryostat neck, one must worry about the added heat leak coming down the neck and the thermal acoustic oscillation heat exchange that might occur in the space between the cooler and the neck tube the cooler. For that reason, GM coolers are often mounted on the superconducting magnets in the vacuum space of the cryostat. This makes the required cold head maintenance more difficult.

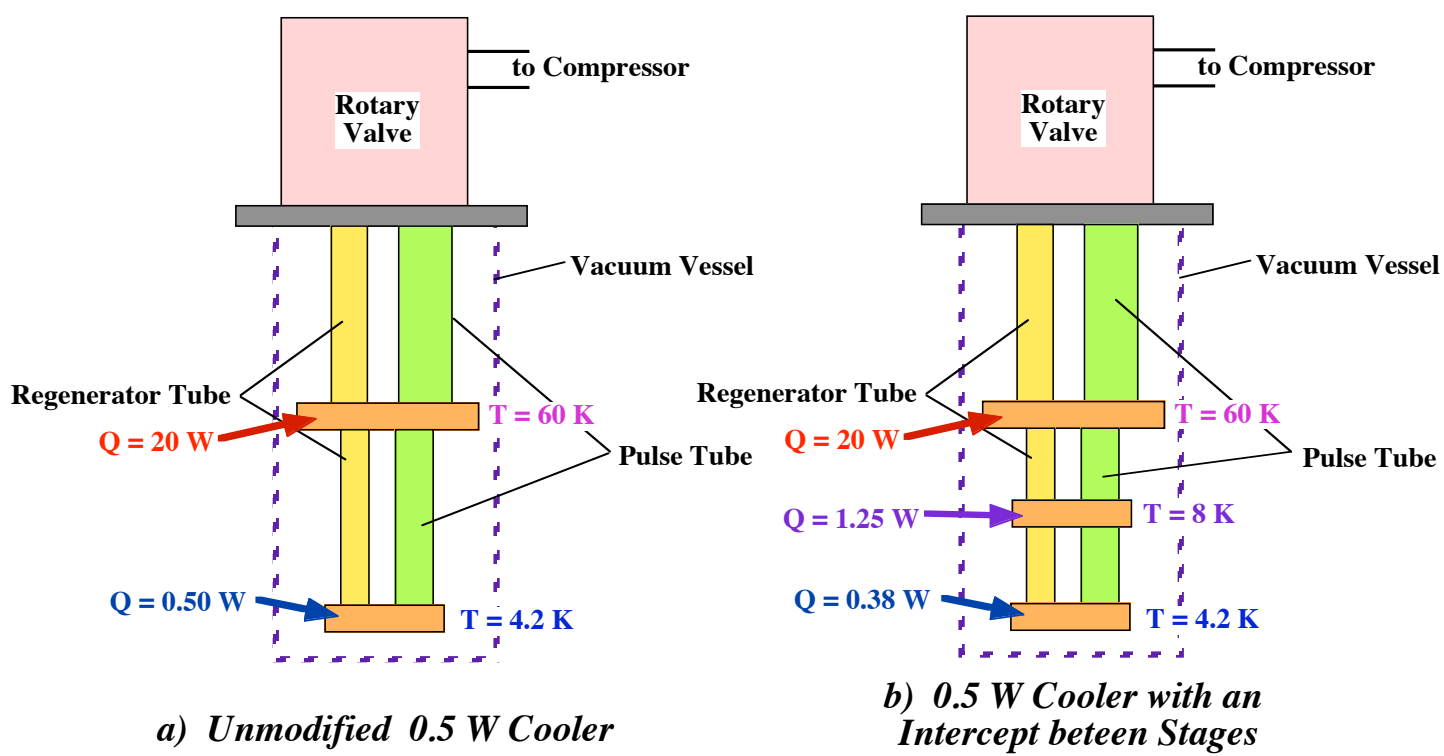

Figure 3. In Illustration of an Experiment done Some Years Ago with a 0.5 W Pulse Tube Cooler (This experiment shows that cooling at different temperatures can occur on the pulse tubes and regenerator tubes of certain types of pulse tube.)

Figure 3 shows an experiment that was done using a $0.5 \mathrm{~W}$ cooler (at $4.2 \mathrm{~K}$ ). This figure illustrates that as one moves up the tubes, the temperature increases and the amount of refrigeration available increases as well [9]. It is interesting to note that not all pulse tube coolers exhibit this property to the degree shown in Figure 3. It is clear that this phenomenon also occurs above the first stage. This explains why some pulse tube coolers can be installed in a helium-filled neck of a superconducting magnet and the heat flow into the magnet goes down. Helium gas flows down the surface of cooler tubes and it flows up the surface of the neck tube. Heat coming down the neck is intercepted by the gas flowing up the neck tube. The intercepted heat is delivered to the cooler tubes at a variety of temperatures, where more refrigeration is available.

The ability to deliver more refrigeration at higher temperature as one moves up the tubes of a pulse cooler is important if one wants to efficiently liquefy hydrogen or helium. Cryomech has built a number of helium liquefiers. Figures 4 shows one the earliest versions of the Cryomech PT-410 cooler used as a helium liquefier. 


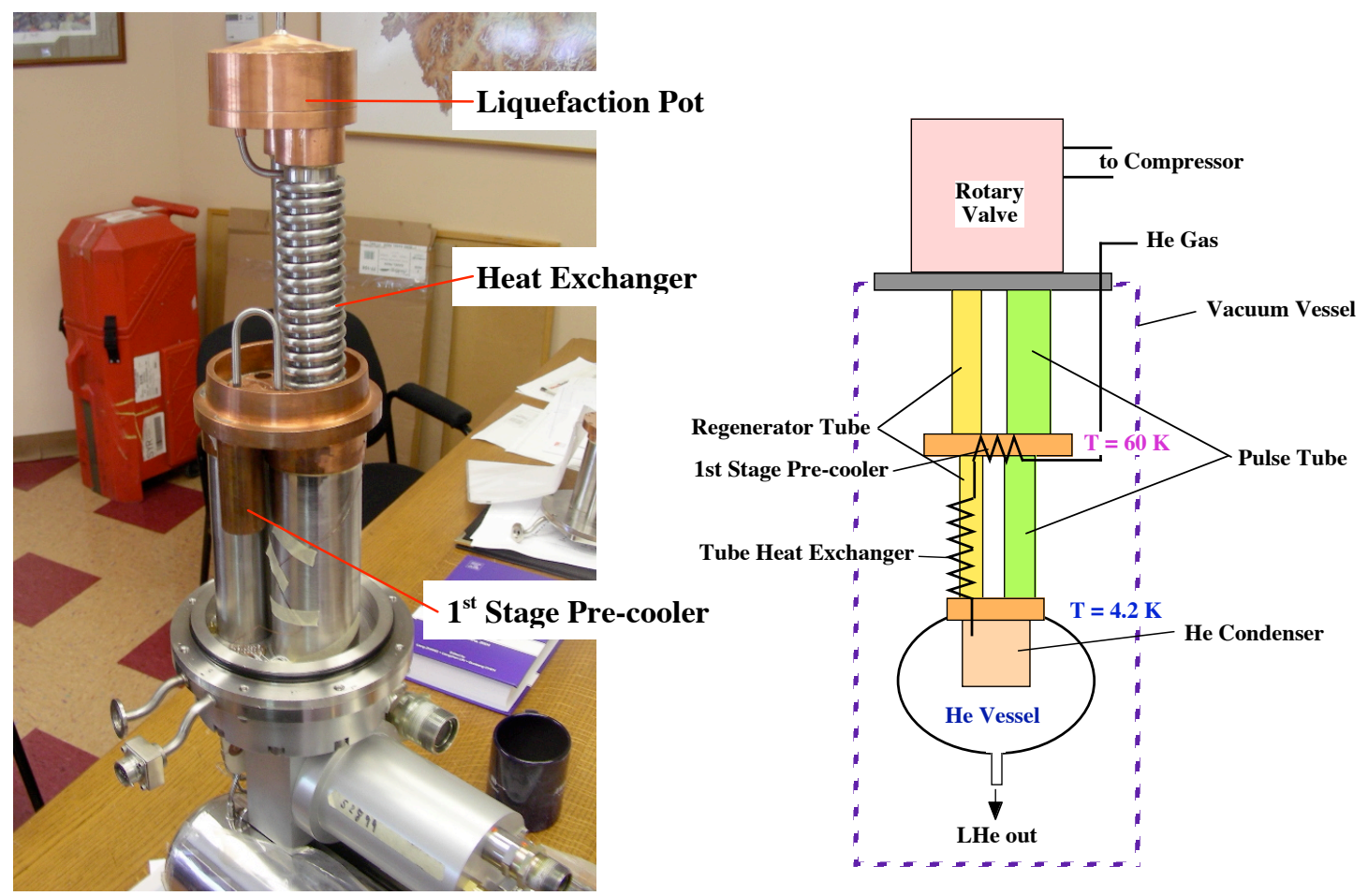

Figure 4. A Helium Liquefier Based on a PT-410 Pulse Tube Cooler. The photo on the left shows the cooler (upside down) with $1^{\text {st }}$ stage heat exchanger and the liquefier pre-cooling attached to the $2^{\text {nd }}$ stage regenerator tube. The diagram to the right shows a schematic of the first helium liquefier to the left.

The pulse tube helium liquefier shown in Figure 4 liquefies $0.022 \mathrm{~g} \mathrm{~s}^{-1}$ using a cooler that produces $1.0 \mathrm{~W}$ at $4.2 \mathrm{~K}$, on the second-stage cold head. The refrigeration to liquefaction coefficient for the liquefier is $\sim 45 \mathrm{~J} \mathrm{~g} \mathrm{~g}^{-1}$, which is better than large helium liquefiers [10]. This is only a little over a factor of two more than the perfect liquefier. No other type of liquefier using a small cooler comes close to this performance. The liquefier shown in Figure 4 is now being used at the south pole to re-liquefy helium in a 4000 liter storage tank that previously had a boil-off of fourteen liters per day (about $0.0203 \mathrm{~g} \mathrm{~s}^{-1}$ ). The same tank with the liquefier, has no helium boil-off. In addition, the liquefier can make three liters of helium per day (about $0.0043 \mathrm{~g} \mathrm{~s}^{-1}$ ) from the helium recovery tanks on the site. The performance of the liquefier was better within the large south-pole liquid helium tank than in a 60 liter dewar. The ability to reduce the heat leak in a cryostat neck by using free-convection between the cooler tubes above the first-stage and the neck is an important factor in the improved performance.

The machine shown in Figure 4 has a couple of down sides. First, the liquefier heat exchangers are subject to clogging with dirty input gas. This factor may be important for a MICE hydrogen liquefier that takes its gas out of a hydride bed rather than grade A hydrogen from bottles. Second, even though the liquefier shown above looks simple, it is expensive to fabricate. One should ask the question, "Is it better to transfer heat using surfaces of all of the tubes in the cooler as well as using the surfaces in holes that pass through the first and second stage copper blocks?" The cooler shown in Figure 4 could also cool down the 60 liter dewar in about 16 hours, when the cooler and the dewar were both at $300 \mathrm{~K}$ initially. It was clear that the heat leak down the 60 liter dewar neck was reduced, by free-convection cooling between the neck and the cooler. 


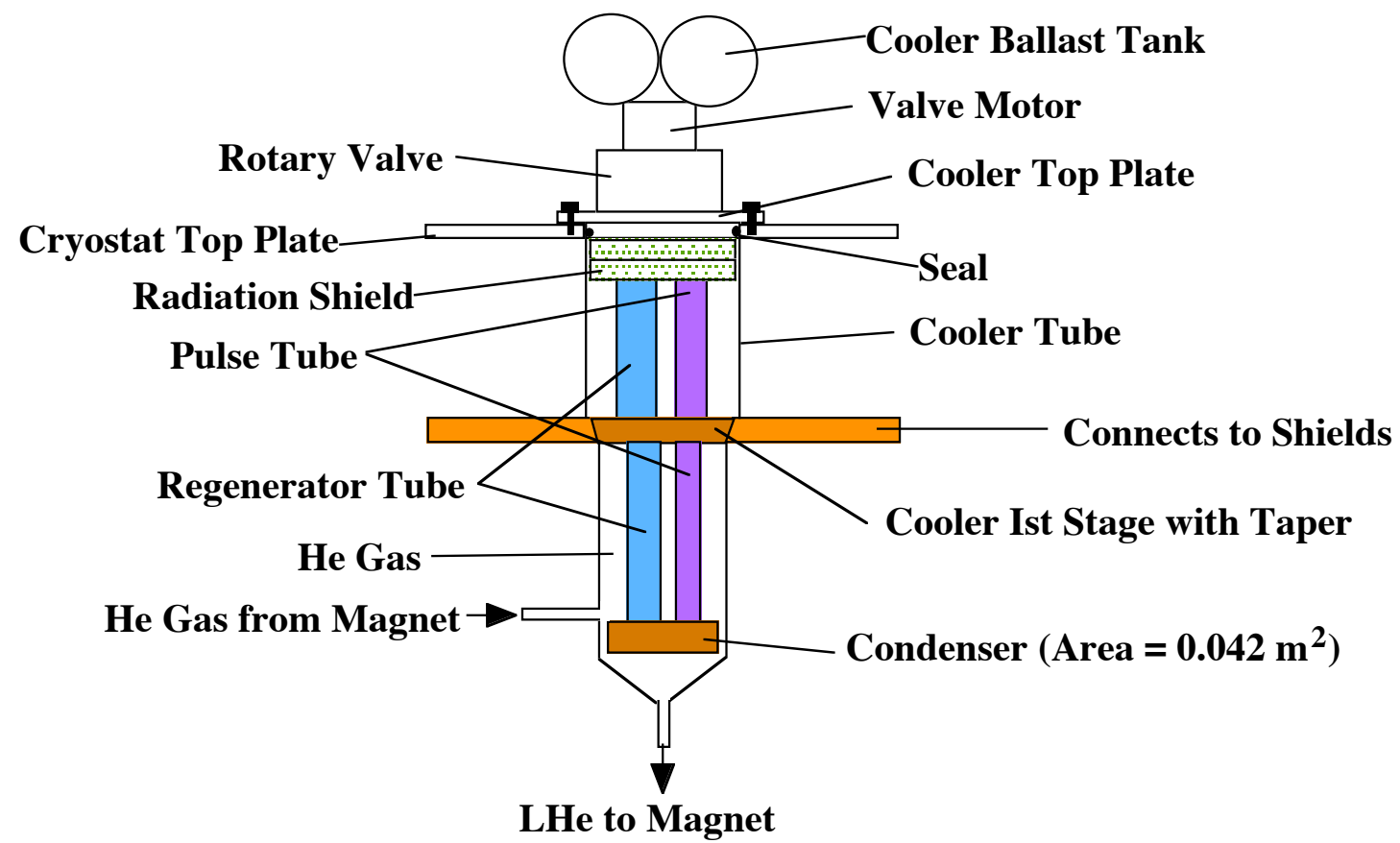

Figure 5. An Illustration of Mounting the PT-415 Cooler into the Neck of a MICE Magnet Cryostat

(The key element is free-convection heat transfer between the cooler tubes and the neck.)

Figure 5 illustrates how a pulse tube cooler can be mounted in the helium-filled neck of a superconducting magnet. The arrangement shown in Figure 5 allows the heat leak down the neck to be intercepted by free-convection currents between the neck and the cooler tubes. This arrangement allows for the easy removal of the cooler from the magnet. This is important to MICE, because the magnets will be tested at the vendor and then they will be shipped to where the magnetic measurements will be done. After doing the magnetic measurements, the magnets will be shipped to the Rutherford Appleton Laboratory for final installation into MICE. The cooler can be shipped separately from the magnet, which could be an advantage for MICE.

Given the vigorous free-convection that occurs off of the regenerator tubes and pulse tubes, Cryomech has tried the concept of free convection off of the tubes in its latest version of a helium liquefier using the PT-410 cooler. The liquefaction was improved by about thirty percent (from $0.022 \mathrm{~g} \mathrm{~s}^{-1}$ to about $0.028 \mathrm{~g} \mathrm{~s}^{-1}$ ), even though the tube heat exchanger was completely eliminated [11]. The refrigeration to liquefaction coefficient for the new liquefier design is $\sim 36 \mathrm{~J} \mathrm{~g}^{-1}$, which is phenomenal performance. The firststage heat exchanger became the cooler tube surfaces and a large number of $5 \mathrm{~mm}$ holes through the copper piece that comprises the cooler first-stage. The second stage heat exchanger is the cooler tube surfaces. The condenser section is the holes in the copper piece that comprises the second-stage of the cooler. As a result, the resulting liquefier is not only more efficient, but it is cheaper to build. A liquefier with parallel paths for gas flow and heat transfer to the tube surfaces far less sensitive to impurities in the gas being liquefied. The impurities in the gas will reduce the heat transfer coefficient on the heat transfer surfaces, but they won't stop liquefaction altogether by clogging the tubes that carry the gas with frozen impurities. Figure 6 illustrates how a PT-415 cooler can be used as liquefier for hydrogen into the MICE absorber. 


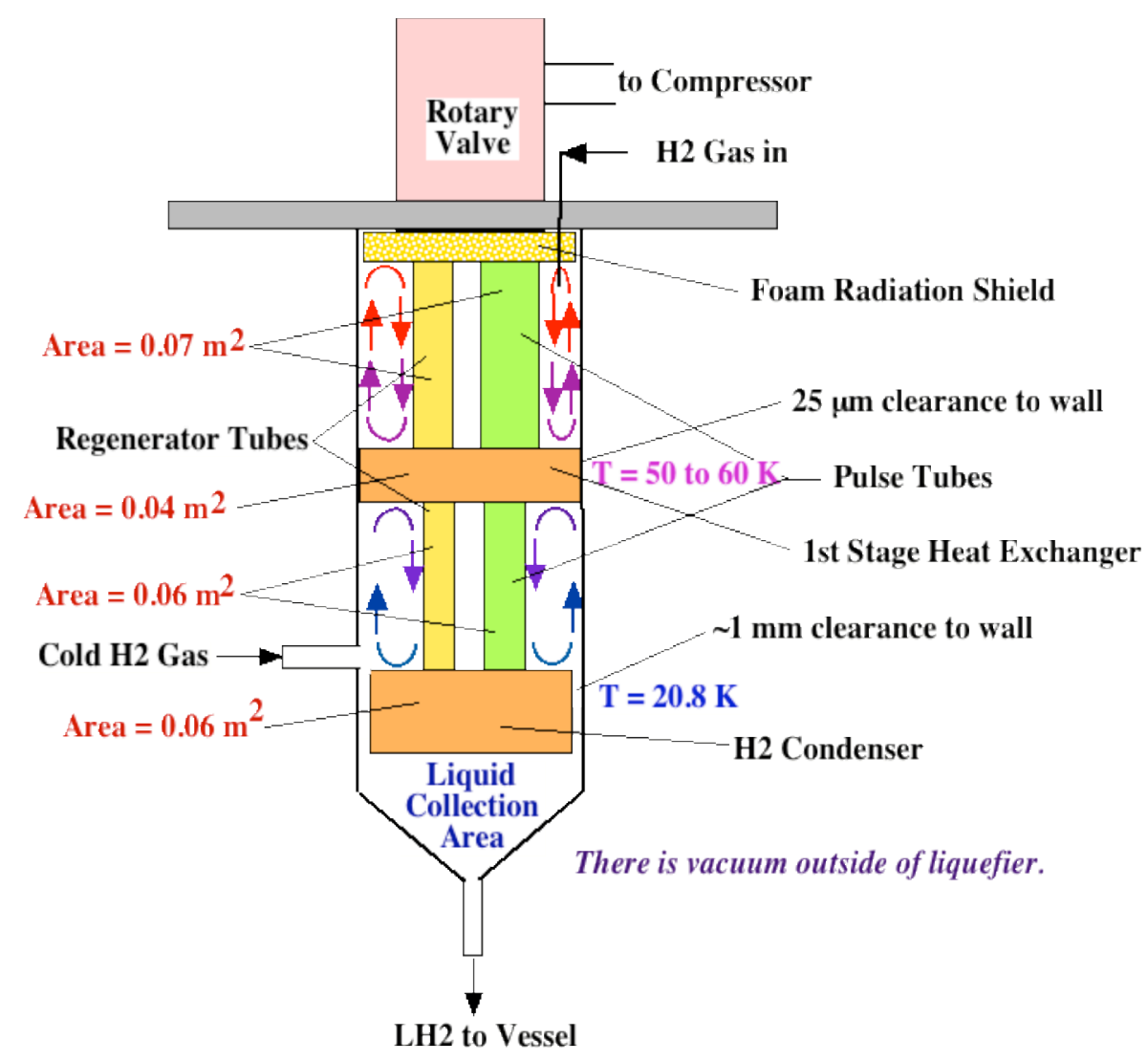

Figure 6. The Cooler Arrangement for a Liquid Hydrogen or Helium Liquefier

Figure 6 is a schematic illustration of how a PT-415 cooler can be used to liquefy hydrogen. The exact same configuration will liquefy helium as well. The heat transfer areas shown in Figure 6 are approximate. The final heat transfer area will come from the final design. The arrangement shown in Figure 6 could be capable of liquefying up to $0.043 \mathrm{~g} \mathrm{~s}^{-1}$ if the scaling between the PT-415 and the PT-410 were proportional to the refrigeration available at 4.2 and $20.8 \mathrm{~K}$ on the second stage. This is an unlikely scenario because; the external heat transfer area of the regenerator and pulse tubes of two coolers does not scale with the available refrigeration at the second-stage. You will note the arrangement shown in Figure 5 and 6 are identical, except for the seal at the first stage (up to 5 or 10 microns clearance) and the holes in the first stage copper plate.

The liquefaction helium at 1.0 bar using a PT-415 cooler in the arrangement shown in Figure 6 could be between 0.035 and $0.039 \mathrm{~g} \mathrm{~s}^{-1}$ (from 1.01 to 1.12 liters per hour). The refrigeration to liquefaction coefficient expected for the arrangement shown in Figure 6 could be in the range from 39 to $43 \mathrm{~J} \mathrm{~g}^{-1}$, which is still excellent. The expected changes in the liquefaction rate for a machine operating on $50 \mathrm{~Hz}$ power is expected to be small, because the available refrigeration on either stage of a PT-415 cooler does not change with line frequency if the cooler compressor is charged to the correct gas pressure for $50 \mathrm{~Hz}$ operation. If the PT-415 cooler used for liquefaction of hydrogen or helium has remote rotary valve and motor. The liquefaction rates can be expected to drop eight to ten percent (not quite as much as the refrigeration available on the second stage). 


\section{The Liquefaction of Hydrogen Gas into the MICE Absorber Using a Cryomech PT-415 Cooler}

The hydrogen liquefier shown in Figure 6 can be the basis for the MICE absorber liquefier. Cryomech is willing to supply the hydrogen (and helium) liquefier for the MICE collaboration, which would include the PT-415 cooler. The two keys to efficient liquefaction of hydrogen or helium are; 1) using the surface area of the pulse tube and regenerator tubes as part of the upper stage heat transfer area, and 2) injecting the hydrogen or helium gas into the liquefier in the correct place. In Figure 6, the hydrogen is shown as entering the space just below the top plate of the cooler. If the hydrogen is injected into the system at another location the efficiency of the liquefaction process will be much lower, because the gas is not pre-cooled by the regenerator tubes, the pulse tubes, and a heat exchanger attached to the first stage, before it enters the condenser section of the liquefier. Figure 7 shows a side view of a configuration of the absorber liquefier that uses a PT-415 cooler as a liquefier.

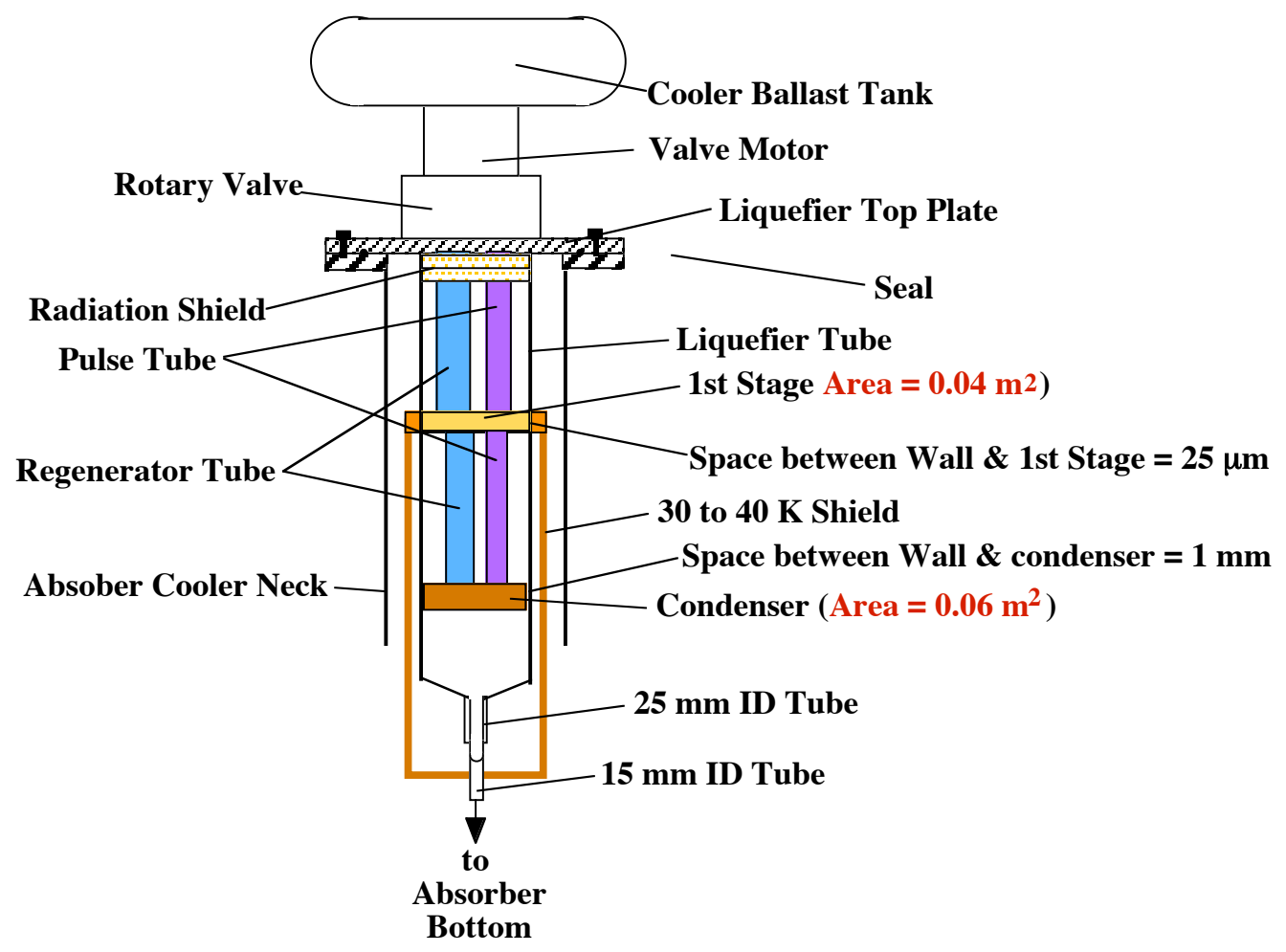

Figure 7. A MICE Absorber Liquefier using a PT-415 Cooler as Seen from the Side of the AFC Module. (Note: the hydrogen surge pot is shown as a vertical cylinder; the pot could be horizontal.)

Figure 7 and 8 are roughly at the same scale. The $529 \mathrm{~mm}$ long tube that the Cryomech PT-415 cooler slips into is a tube that is $129.5 \mathrm{~mm}$ (5 inches) ID with a wall thickness of $0.87 \mathrm{~mm}$ (0.035 inches). This tube is welded into the bottom of the top plate for the liquefier that is approximately $340 \mathrm{~mm}$ long and $180 \mathrm{~mm}$ wide. The top plate has an o-ring seal between the air and the absorber vacuum. Cryomech can fabricate the top plate assembly so that it is bathed in an inert atmosphere (with no oxygen). 


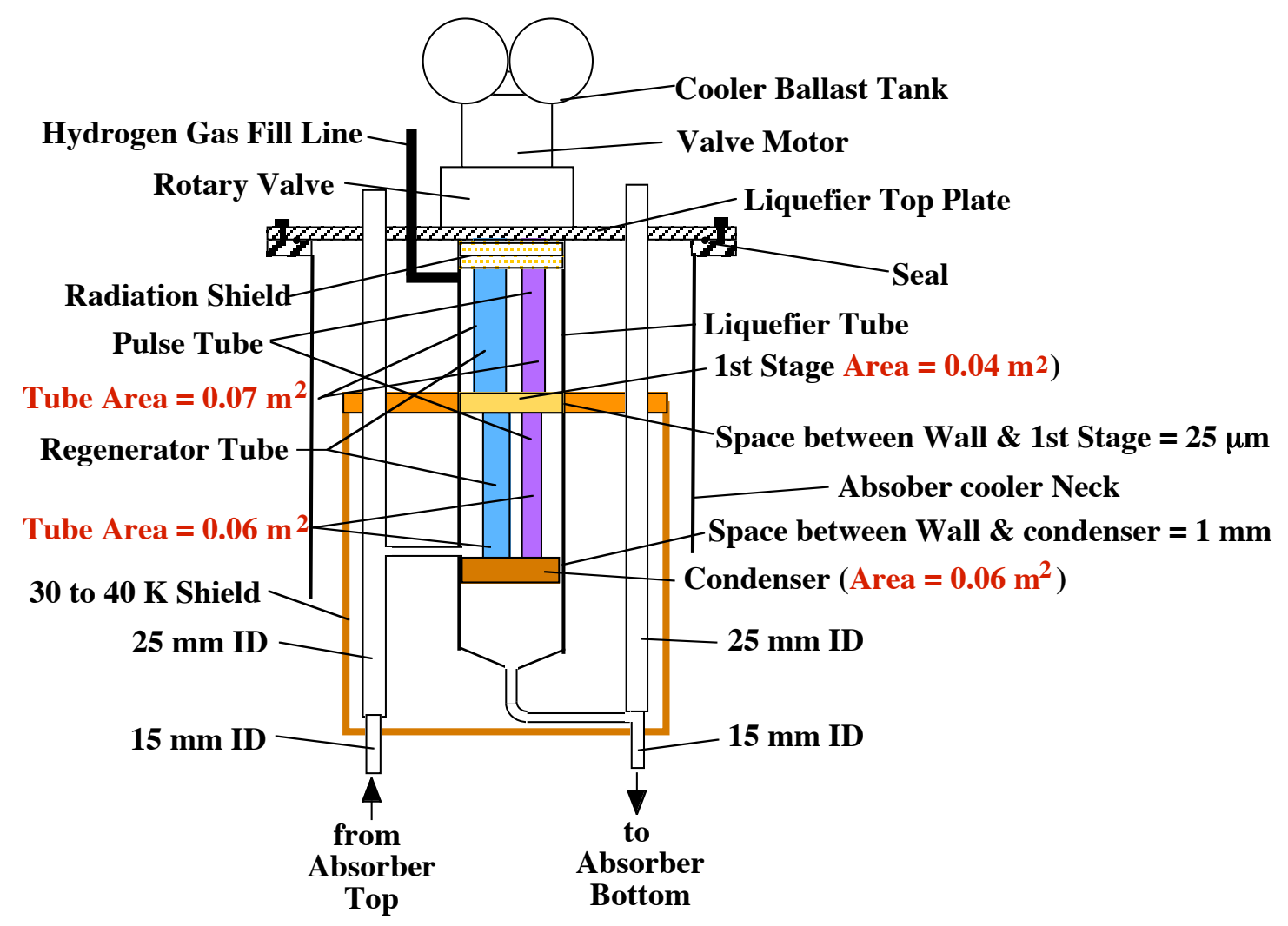

Figure 8. A MICE Absorber Liquefier using a PT-415 Cooler as Seen from the End of the AFC Module. (Note: the hydrogen surge pot is shown as a vertical cylinder; it could be horizontal.)

The absorber liquefier as shown in Figures 7 and 8 can be installed in the AFC module separately after the module has been delivered to RAL and the absorber has been installed within the bore of the AFC solenoid. Only two pipe connections need be made between the absorber and the liquefier shown in Figures 6 and 7. The only other connection may be a connection between the first stage shield and any shield on the absorber and the pipes leading to the absorber. This author assumes that the absorber cooling pipes are not connected.

Figure 8 shows the two $25 \mathrm{~mm}$ ID diameter tubes that are part of the relief system for the absorber when it is filled will liquid helium. Below the first stage of the cooler, the relief tubes go down $15 \mathrm{~mm}$ ID. The hydrogen or helium that is liquefied goes to the bottom of the absorber. The other tube comes from the top of the absorber. Both tubes form two independent relief paths for the liquid absorber. The sizing of the pipes is set by liquid helium operation for the absorber. The hydrogen or helium surge pot is below the condenser. Since both liquid hydrogen and liquid helium expand upon heating, the surge volume below the absorber should be at least 1.5 liquid liters.

While the cooler can cool down and liquefy hydrogen into the absorber, the process will take some time (depending on the excess refrigeration available for liquefaction). With $20 \mathrm{~W}$ of excess refrigeration one might be able to fill the absorber (once it is cooled to $20 \mathrm{~K}$ ) with liquid hydrogen in about 24 hours. If there is only $10 \mathrm{~W}$ of excess refrigeration, the time to fill the absorber will go up to something over the order of 48 hours. Shielding the pipes and the absorber by conduction to the first stage of the absorber will play a role in reducing the fill time of the absorber once it is cold. 
The author has assumed that the absorber (roughly $19 \mathrm{~kg}$ of aluminum) can be cooled from room temperature $(300 \mathrm{~K})$ to $10 \mathrm{~K}$ using liquid helium injected into the bottom of the absorber. This means that the vent pipe from the absorber bottom has two extra valves (a ball valve for the bayonet joint and a valve that keeps the helium fill line from venting along with the line that comes from the top of the absorber) in it that allows liquid helium to be injected directly to the bottom of the absorber. The absorber venting when the absorber is cooled down comes off of the top of the absorber. During the cool down the helium gas produced while cooling the absorber would be vented through the hydrogen vent system. If the sensible heat of the helium is used along with the helium heat of vaporization, about 25 liters of liquid helium are needed to cool down the absorber from $300 \mathrm{~K}$ to $10 \mathrm{~K}$. Using liquid helium, the absorber cool down should take less than an hour. The safety issue is making sure that the two valves in the vent line used to fill the absorber with helium for cool down are in the correct operating mode when the absorber is filled with hydrogen.

The line that brings hydrogen gas into the liquefier comes into the liquefier in the space between the liquefier top plate and the first stage of the cooler. This line should come directly from the hydrogen gas source (in the case of MICE the hydride bed) rather that via the hydrogen surge tank and vent system. If the hydrogen gas is fed into the system at this point, the total heat transfer area available for pre-cooling the hydrogen is about $0.21 \mathrm{~m}^{2}$. When the hydrogen is condensed on the second stage, only about $0.02 \mathrm{~m}^{2}$ of area is needed to do the condensing. The flow through the holes in the cooler first stage cooper block and the condenser holes in the upper part of the condenser copper block is laminar. Flow past the cooler tubes could well be turbulent considering the temperature differences in the free-convection heat transfer process. Given that only about $120 \mathrm{~W}$ of heat must be removed from the hydrogen before liquefaction, the temperature differences between the gas and the heat transfer surfaces will be reasonable.

The distance between the top plate of the liquefier shown in Figures 7 and 8 is about $560 \mathrm{~mm}$. This distance is not very different from the distance shown in the AFC reference drawing. If the is distance is larger than shown in the reference drawing the cooler will have to be moved a little further from the central axis of the AFC module. The portion of the cooler that is above the top plate occupies about $350 \mathrm{~mm}$ of space. If the rotary valve and its motor are put in a remote location away from the AFC module, the cooler ballast tank can be in the same location as the valve and its motor. The PT-415 coolers used for the magnets will be about $759 \mathrm{~mm}$ high from the bottom the condenser to the top of the ballast tank. For the proposed absorber liquefier, this height is $910 \mathrm{~mm}$. If the rotary valve is in a remote location the height of the liquefier is about $570 \mathrm{~mm}$.

Like the absorber and the plumbing going into the absorber, the hydrogen liquefier must be built in accordance to the pressure vessel code for flammable gases. While the working pressure of the absorber and its liquefier is set at 1.7 bar, the liquefier like the absorber body must be designed to withstand the burst pressure of the absorber windows without yielding. The pulse tubes and regenerator tubes must not buckle at 6.8 bars. Preliminary calculations suggest that the stress in the cooler tube will be $65 \mathrm{MPa}$ when the pressure inside the tube is 6.8 bars. The worst case buckling pressure for the cooler regenerator tubes and pulse tubes appears to be above 25 bars. Preliminary calculations suggest that the liquefier for the absorber can withstand the burst pressure of the absorber thin windows with a margin of at least a factor of three. If Cryomech were to produce the absorber liquefier as safety analysis would have to be part of the design. 


\section{The Proposed LBNL PT-415 Cooler Experiment}

It has been proposed that an experiment be done using one of the PT-415 coolers that has been purchased for the tracker solenoid. The primary reasons for doing an experiment with the PT-415 cooler are as follows: 1) One should measure the operating diagram for the cooler over a range of first-stage heat loads from 0 (a few watts) to $80 \mathrm{~W}$. At the same time heat loads from 0 (a few tenths of a W) to $30 \mathrm{~W}$ will be applied to the second stage of the cooler. The operating diagram will be measured in vacuum and with the cooler in an atmosphere of helium gas. An operating diagram for a PT-415 is shown in Figure 9, but the operating diagram does not extend up to $30 \mathrm{~W}$ on the second stage.

2) The purpose of the test is to confirm that cooler will operate in a magnet cryostat with the cooler in a drop in mode. One should measure the extra heat leak that might occur from operating the cooler in this mode. 3) The $\Delta \mathrm{T}$ between the shield and the first stage of the cooler across the press fit joint will also be measured in vacuum and in helium gas. The degree to which convection currents in the space between the cooler and the tube holding the cooler reduces the heat leak into the experiment will be measured.

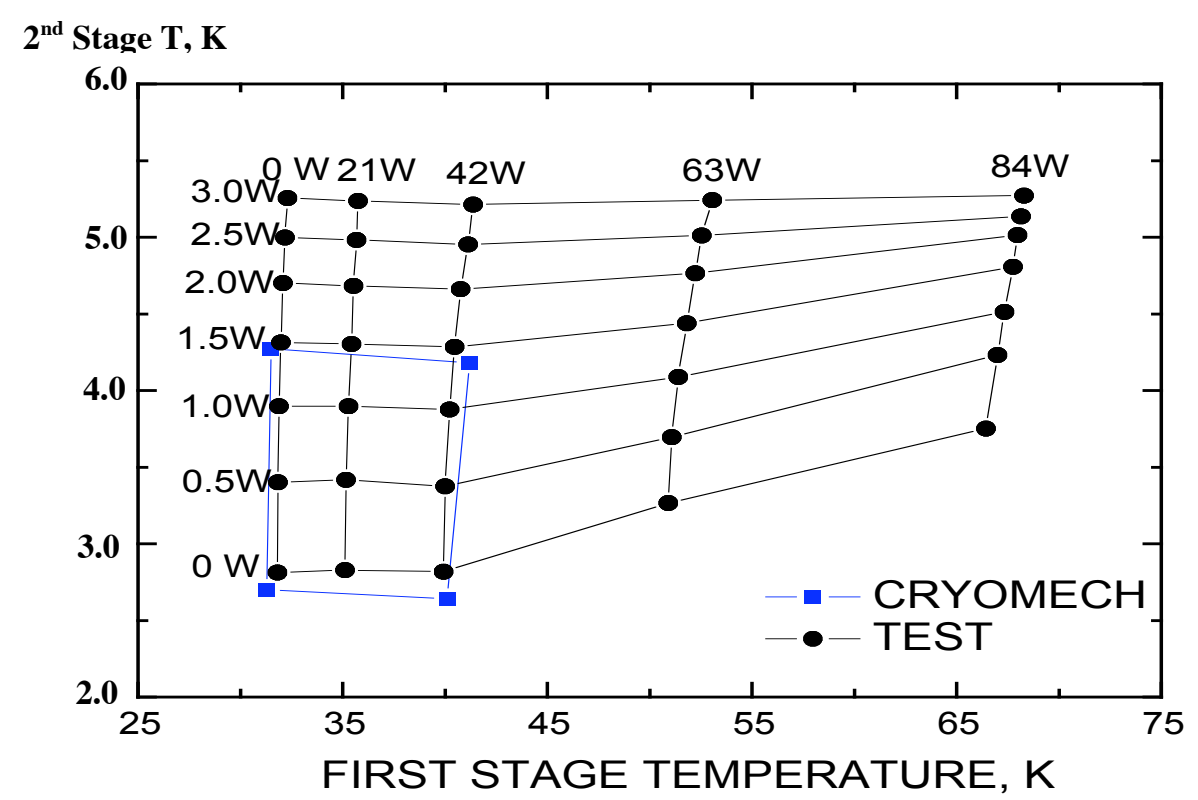

Figure 9. The Operating Diagram for the PT-415 Cooler with up to $3 \mathrm{~W}$ on the Second-Stage (The measurements were taken by Tom Painter at the National High Field Magnet Laboratory [12].)

It will be very useful to operate the experiment with liquid helium in the liquid pot at temperatures that range from $3.8 \mathrm{~K}$ to $4.6 \mathrm{~K}$. The temperature drop between the second stage cold head and the liquid helium in the liquid pot can be measured depending on the accuracy of the thermometry. Operation of the experiment at temperatures below $4.22 \mathrm{~K}$ means that the pressure in the helium pot will be sub-atmospheric.

A secondary reason for doing the experiment is to measure the liquefaction rate for hydrogen and helium when the gas enters the cooler chamber at $300 \mathrm{~K}$. The liquefaction rate for the experiment shown in Figure 10 is expected to be lower than for the liquefier shown in Figures 7 and 8. The surface area above the condenser is reduced to $0.15 \mathrm{~m}^{2}$ instead of the $0.22 \mathrm{~m}^{2}$. This will reduce the liquefaction by up to 30 percent. 


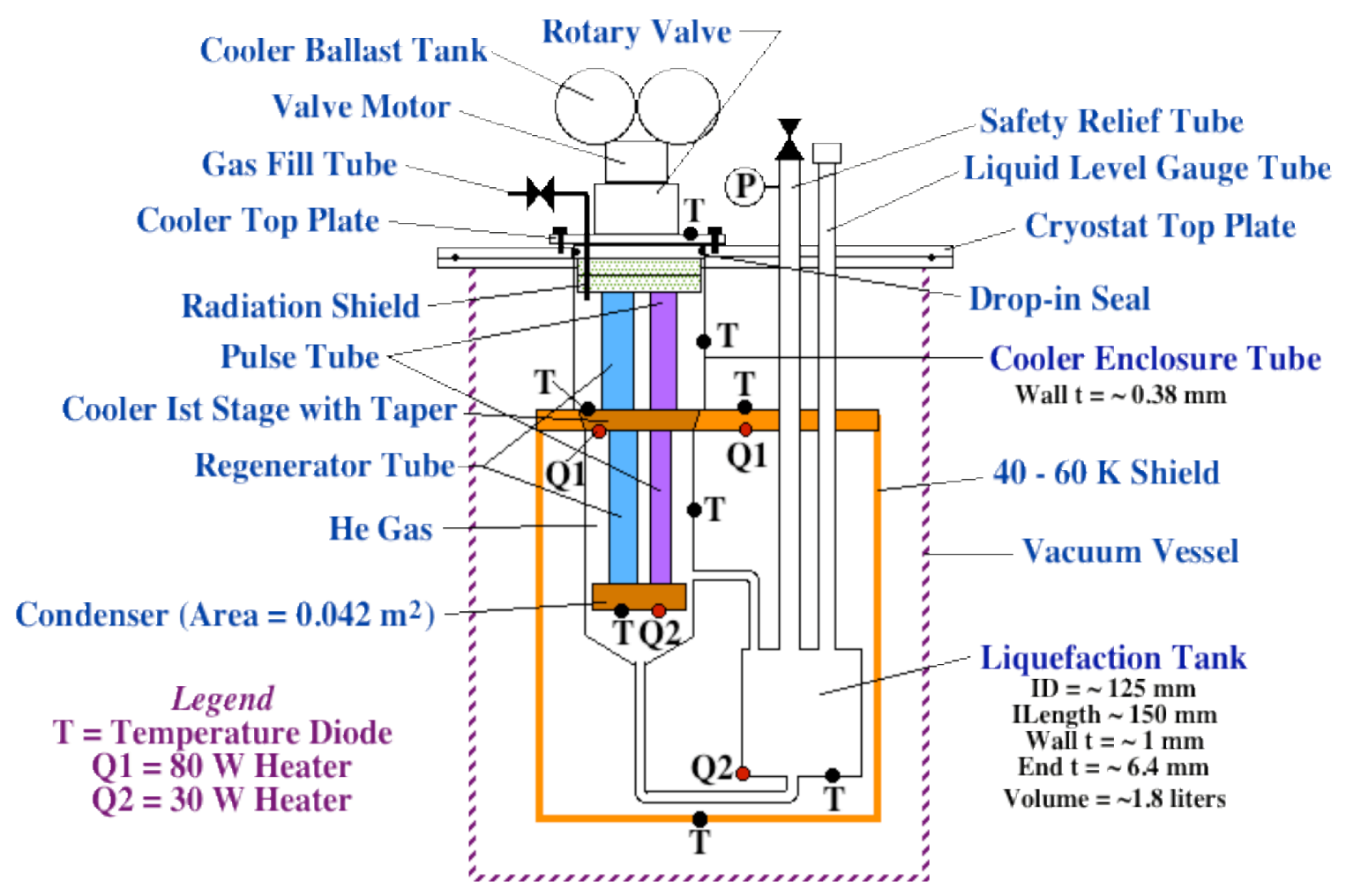

Figure 10. A Schematic Representation of the Proposed LBL Cooling Experiment for Measuring the Operation Characteristics and Liquefaction of a PT-415 Cooler as it Will be Used in the Tracker Magnet

The schematic shown in Figure 10 shows the proposed location of the diode temperature sensors $\mathrm{T}$, the $80 \mathrm{~W}$ heaters used to measure the performance of the first stage, and the $25 \mathrm{~W}$ heaters used to measure the performance of the cooler second stage.

The experiment will first be done with the chamber around the cooler and the liquefaction tank evacuated. The operating characteristic will be measured as they were in Figure 9 over a range of heats into the first stage heaters starting at zero and going up to $80 \mathrm{~W}$ in steps of $20 \mathrm{~W}$. At the same time heat will be put into the second stage of the cooler through the heater attached to that stage. From 0 to $2 \mathrm{~W}$, the interval will be in steps of $0.5 \mathrm{~W}$. When the heat into the second stage is $2 \mathrm{~W}$, the heat in the second stage will be increased to $5 \mathrm{~W}$. From $5 \mathrm{~W}$ to $30 \mathrm{~W}$, the interval will be $5 \mathrm{~W}$. When the heat load into the second stage is $30 \mathrm{~W}$, the temperature of the second stage is expected to be over $25 \mathrm{~K}$. Temperature measurements will be made using the temperature diodes on the cooler first stage of the cooler and diodes mounted on the shield near the press fit interface and the diode on the bottom of the shield. The temperatures measured by the three diodes will be compared. The temperature will also be measured on the cooler second stage and on the outside surface of the liquefaction tank. The temperature will be measured on the cooler chamber tube at a position half way between the cooler top plate and the cooler first stage. The temperature will also be measured on the cooler chamber tube half way between the cooler first-stage and the second-stage.

The experiment above is repeated with helium gas in the chamber around the cooler and in the liquefaction tank. The pressure of the helium will be just above 1 bar, Liquefaction of the helium on the condenser will only occur when the second stage temperature is below the saturation temperature for the helium in the tube. 
Once the temperature is low enough to liquefy helium, the liquefaction rate will be measured using a liquid helium level probe that is in the liquefaction chamber. Once helium liquefaction has commenced, the temperature measured by the diode on the bottom of the liquefaction chamber should read the same temperature (within $0.1 \mathrm{~K}$ ) as the temperature diode mounted on the cooler second stage. The temperature measured by both diodes should correspond to the saturation temperature of helium at the pressure that is measured at the pressure gauge at room temperature. Once the liquefaction chamber is half filled with liquid helium, the $30 \mathrm{~W}$ heater on the liquefaction chamber is used to raise and lower the temperature and pressure of the helium in the liquefaction chamber. (The heater on the cooler second stage is shut off.) In general, the liquid level is expected to rise as the helium is heated.

Once the liquid helium experiments are finished, the helium is boiled away. The cooler chamber and the liquefaction chamber are evacuated and the cooler second stage is allowed to cool to about $10 \mathrm{~K}$. Hydrogen gas will be introduced and the pressure will be allowed to rise to just above 1 atmosphere. Hydrogen liquefaction should commence on the condenser on the cooler second stage. Once liquid hydrogen has collected in the liquefaction pot, the liquefaction rate will be measured. Hydrogen liquefaction will stopped by turning on the $30 \mathrm{~W}$ heater on the outside of the liquefaction pot. It is hoped that the hydrogen liquefaction rate can be measured as a function of the heat input into the bottom of the liquefaction pot by the heater. The total amount of liquid hydrogen to be liquefied will be limited to about 1 liquid liter.

The diode temperature sensors will be calibrated diodes from Lakeshore Cryotronics. The liquid helium level gauge will be a superconducting liquid helium level gauge from American Magnetics. The liquid hydrogen level gauge will be a capacitance type liquid level gauge from American Magnetics.

\section{Some Concluding Comments}

The production of refrigeration at $4.5 \mathrm{~K}$ came shortly after the first two stage GM coolers were built. In order to get temperatures as low as $4 \mathrm{~K}$, a separate J-T loop attached to the cooler has to be used. Unfortunately the early $4 \mathrm{~K}$ coolers were unreliable and could not be used as liquefiers.

The advent of $4.2 \mathrm{~K} \mathrm{GM}$ coolers using rare earth regenerators on the second-stage combined with HTS leads made it possible to reliably cool low Tc magnets with a small cooler. Because the coolers themselves could produce $4.2 \mathrm{~K}$, liquefaction using a separate J-T loop became improved. The unreliability problems associated with the separate J-T circuit still remains. GM coolers can be used for liquefaction of helium or hydrogen provided that there is sufficient cooling off of the cooler first stage. Liquid nitrogen pre-cooling of the gas improves liquefaction even more.

$4 \mathrm{~K}$ Pulse tube coolers can also be used for helium and hydrogen liquefaction. It is useful to point out that not all pulse tube coolers are alike when they are used as liquefiers. Cryomech pulse tube coolers can produce a large amount of cooling at higher temperatures on the pulse tubes and regenerator tubes. This feature combined with holes in the first and second stage copper blocks permit one to have enough pre-cooling in the gas to be liquefied. As a result low refrigeration to liquefaction coefficients can be achieved for both hydrogen and helium gas.

Using the PT-415 Cryomech Cooler (a pulse tube cooler that produces $1.5 \mathrm{~W}$ of cooling at $4.2 \mathrm{~K}$ ), one can achieve maximum liquefaction rates for hydrogen of about one 
liter per hour. For MICE there are three things that one must do to maximize the hydrogen liquefaction rate. 1) The heat leak into the cooler and the absorber must be minimized. 2) The hydrogen must be injected in the top of liquefaction column so that it can be pre-cooled on all the tubes and the first stage heat exchanger. 3) While the cooler can cool down the absorber, liquefying into a pre-cooled absorber (down to $10 \mathrm{~K}$ ) will minimize the time to fill the absorber with liquid hydrogen. Cryomech can produce the hydrogen liquefaction module for the AFC modules for MICE.

\section{Acknowledgements}

The author wishes to thank Chao Wang and Peter Gifford of Cryomech Incorporated of Syracuse, New York, USA for their information about the operation of their $4.2 \mathrm{~K}$ pulse tube coolers and the use of their pulse tube coolers as helium liquefiers.

This work was supported by the Office of Science, United States Department of Energy, under DOE contract DE-AC02-05CH11231. DOE funding for the US Neutrino Factory and Muon Collider Collaboration is also gratefully acknowledged.

\section{References}

[1] G. Gregoire, G. Ryckewaert, L. Chevalier, et al, "MICE and International Muon Ionization Cooling Experiment Technical Reference Document,"(October 2004)

[2] W. E. Gifford, "The Gifford McMahon Cycle," Advances in Cryogenic Engineering 11, p 152, (1965)

[3] S. Suzuki and S. Ishimoto, "Absorber R and D Test Reports," presented at the $16^{\text {th }}$ MICE Collaboration Meeting, Rutherford Appleton Laboratory, http://hep04.phys.iit.edu/cooldemo/cm/cm16

[4] Victor J. Johnson Ed., A Compendium of the Properties of Materials at Cryogenic Temperature, Pergamon Press, New York (1961)

[5] W. E. Gifford, N. Kadaikkal, and A. Acharya, "Simon Helium Liquefaction Method using a Refrigerator and Thermal Valve," Advances in Cryogenic Engineering 15, p 422 (1969)

[6] M. Sahashi, Y. Tokai, T. Kuriyama et al, "New Magnetic Material $\mathrm{R}_{3}$ T System with Extremely Large Heat Capacities used as Heat Regenerators," Advances in Cryogenic Engineering 35, p 1175 (1990)

[7] M. A. Green, "Cooling the MICE Liquid Hydrogen Absorbers using Small Cryogenic Coolers," Oxford University Physics Department Note 9, MICE Note 108, 3 September 2004

[8] C. Wang and P. E. Gifford, "Development of 4 K Pulse Tube Cryo-refrigerators at Cryomech," Advances in Cryogenic Engineering 47, p 491, (2001)

[9] C. Wang of Cryomech Incorporated private communication concerning cooling on pulse tubes and regenerator tubes, December 2006

[10] C. Wang, "Small helium Liquefiers using 4 K Pulse Tube Cryocoolers," Advances in Cryogenic Engineering 51, p 829 (2005)

[11] C. Wang of Cryomech Incorporated private communication concerning open helium liquefiers, December 2006

[12] T. Painter, National High Magnetic Field Laboratory, Florida State University, private communication concerning the performance of a PT-415 cooler. 


\section{DISCLAIMER}

This document was prepared as an account of work sponsored by the United States Government. While this document is believed to contain correct information, neither the United States Government nor any agency thereof, nor The Regents of the University of California, nor any of their employees, makes any warranty, express or implied, or assumes any legal responsibility for the accuracy, completeness, or usefulness of any information, apparatus, product, or process disclosed, or represents that its use would not infringe privately owned rights. Reference herein to any specific commercial product, process, or service by its trade name, trademark, manufacturer, or otherwise, does not necessarily constitute or imply its endorsement, recommendation, or favoring by the United States Government or any agency thereof, or The Regents of the University of California. The views and opinions of authors expressed herein do not necessarily state or reflect those of the United States Government or any agency thereof, or The Regents of the University of California. 


\title{
The Liquefaction of Hydrogen and Helium using Small Coolers
}

\author{
Michael A. Green \\ Lawrence Berkeley National Laboratory \\ Berkeley CA 94720, USA
}

12 February 2007

* This work was supported by the Lawrence Berkeley Laboratory and the Office of Science, U.S. Department of Energy under Contract No. DE-AC02-05CH11231 